\title{
The effect of vitamin $D$ on enzyme activities in the rat
}

\author{
By ELISABETH M. CHEESMAN, ALICE M. COPPING AND \\ PATRICIA M. PREBBLE \\ Departments of Nutrition and Physiology, Queen Elizabeth College \\ (University of London), Campden Hill Road, London, $W 8$ \\ (Received 7 August 1963-Accepted 31 October 1963)
}

Histochemical methods offer the advantage, in the study of vitamin deficiency states, that a considerable amount of information can be obtained from each animal. The amount of tissue required for the demonstration of any one enzyme is small; thus the number of enzymes that can be examined is virtually unlimited.

In this study a comparison was made of enzyme activities in tissues of normal and vitamin D-deficient rats. 'The tissues, other than bone, where lack of vitamin $\mathrm{D}$ is considered to have an effect, are those associated with calcium and phosphorus absorption and excretion and those associated with the control of calcium and phosphorus metabolism. The intestine and its associated glands, and the kidney and the parathyroid gland have therefore been selected for investigation.

\section{EXPERIMENTAL}

\section{Animals}

The rats were of the Lister Institute black and white stock maintained at Queen Elizabeth College. They were weaned at 23 days and taken for experiment at 28-30 days at weights ranging from 57 to $80 \mathrm{~g}$. The histological procedure required pairs of animals for comparison, and limitation of time permitted only two or four animals to be dealt with in a week. Pairs of male rats were therefore taken for experiment at intervals, caged separately and fed on Steenbock's rachitogenic diet 2965 (Steenbock \& Black, 1925) with or without a dose of vitamin D. Vitamin D was given as a solution of Adexolin (a concentrate of vitamins A and D; Glaxo Research Ltd) in arachis oil in a single weekly dose of ro i.u. vitamin $D$. The animals without vitamin $D$ received arachis oil to compensate for any effect of the inclusion of the small amount of oil in the diet. The diet was offered as a dry powder and was made once or twice weekly. It consisted of freshly ground whole yellow maize complete with the germ $76 \%$, wheat gluten $20 \%$, calcium carbonate $3 \%$, and sodium chloride $1 \%$, with a $\mathrm{Ca}: \mathrm{P}$ ratio of $4: 1$.

At the beginning of the experiment 'line tests' (Bills, Honeywell, Wirick \& Nussmeier, 193I) were made on the right radius and ulna of every rat on the day it was killed. The left radius and ulna were put into the deep freeze and examined all at the same time at the end of the experiment. The femur, tibia and fibula from all rats were kept in the deep freeze until the end of the experiment so that all bone ash determinations could be done at the same time. Bone ash was measured by the method of 
Hume, Pickersgill \& Gaffikin (1932) and the results were calculated as percentage ash in the dry fat-free bone.

The initial study was made on rats maintained for 4 weeks on the rachitogenic diet. Later studies were made on animals maintained for 4,5 , and 7 weeks on the diet.

\section{Preparation of tissues}

After the animals had been stunned, the thorax was opened and the large vessels were severed. Tissues were placed on metal chucks previously cooled with solid carbon dioxide and transferred to a cryostat maintained at $-27^{\circ}$. Sections were cut at $10 \mu \mathrm{m}$ with the cryostat and collected on coverslips.

Tissues were taken from one normal and one deficient animal each day. 'The pairs of animals were always litter-mates and were taken in random order. They were not identified as normal or deficient until all comparisons had been completed.

The first $\mathrm{cm}$ of the intestine is referred to as duodenum. A specimen taken about $8 \mathrm{~cm}$ from the pylorus is referred to as jejunum; here Brunner's glands are absent.

\section{Histochemical methods}

Alkaline phosphatase was demonstrated by the calcium-cobalt method of Gomori (Pearse, 1960, p. 868) without prior fixation. Duodenum, jejunum and kidney were incubated for 2 and $5 \mathrm{~min}$ at room temperature, ileum, colon, liver and parathyroid for $45 \mathrm{~min}$ at $37^{\circ}$.

Acid phosphatase was demonstrated by the lead-nitrate method of Gomori (Pearse, 1960, p. 88I) with prior fixation in acetone at $0-4^{\circ}$ and fixation in $4 \%(\mathrm{v} / \mathrm{v})$ formaldehyde immediately after incubation. Duodenum, jejunum, kidney, liver, pancreas and parathyroid were incubated for 20 and $40 \mathrm{~min}$ at room temperature, ileum and colon for $30 \mathrm{~min}$ at $37^{\circ}$.

Glucose-6-phosphatase was demonstrated by the lead method of Wachstein $\&$ Meisel (Pearse, 1960, p. 880) with no prior fixation. All tissues were incubated for Io and $20 \mathrm{~min}$ at room temperature.

Lactate dehydrogenase was demonstrated by the method of Hess, Scarpelli \& Pearse (Pearse, 1960, p. 912). All tissues were incubated for $30 \mathrm{~min}$ at $37^{\circ}$.

Leucine aminopeptidase was demonstrated by the method of Nachlas, Crawford $\&$ Seligman (Pearse, I960, p. 9r3). Duodenum, jejunum and kidney were incubated for $15 \mathrm{~min}$ at $37^{\circ}$, parathyroid, pancreas and liver for $45 \mathrm{~min}$ at $37^{\circ}$.

Lipases were demonstrated by the Tween method of Gomori (Pearse, 1960, p. 888) with prior fixation in $4 \%(v / v)$ formaldehyde. Liver was incubated for $\mathrm{I} \frac{1}{2} \mathrm{~h}$ and all other tissues for $4 \mathrm{~h}$ at $37^{\circ}$.

\section{Histochemical scoring}

Pairs of sections were examined with a Greichert bridge comparator and scored as below:

+2 normal much greater activity than deficient,

+ I normal greater activity than deficient,

o no difference in activity,

- I deficient greater activity than normal,

-2 deficient much greater activity than normal. 


\section{RESULTS}

\section{Weight increases and bone changes}

The rats receiving vitamin $\mathrm{D}$ showed some superiority in weekly weight gains over 4,5 and 7 weeks. The differences as shown in Table I were significant $(P<0.01)$ in all groups. These differences may have been partly due to the fact that by using Adexolin as a source of vitamin D a weekly dose of 60 i.u. vitamin A was given in excess of the provitamin A present in the yellow maize which formed most of the diet.

The preliminary line tests showed great differences in calcification in the bones of the rats with and without vitamin D. Subsequent line tests on bones that had been frozen for up to 3 months showed similar patterns of calcification. The differences in calcification were confirmed by the results of bone ash determinations (Table I). 'The differences in percentage of bone ash between animals with and without vitamin $D$ were significant $(P<0.01)$ after 4,5 and 7 weeks on the rachitogenic diet.

In the rats maintained for 7 weeks on the rachitogenic diet there was slight greying of the black hair of the hood and around the eyes. This was suggestive of pantothenic acid deficiency (Blunt, Cheesman \& Copping, 1957) and occurred in rats given or not given vitamin $\mathrm{D}$. It was probable that the maize and gluten diet was not adequate in vitamins of the $B$ complex, but no supplements were given as we did not want to alter the conditions of the test at this stage.

Table I. Mean values with their standard errors for weight gain and percentage bone ash of rats given a rachitogenic diet with or without vitamin $D$

\begin{tabular}{|c|c|c|c|c|}
\hline $\begin{array}{l}\text { Dosing } \\
\text { period } \\
\text { (weeks) }\end{array}$ & $\begin{array}{c}\text { Weekly } \\
\text { dose of } \\
\text { vitamin } D \\
\text { (i.u.) }\end{array}$ & $\begin{array}{l}\text { No. of } \\
\text { rats }\end{array}$ & $\begin{array}{l}\text { Weekly weight gain } \\
(\mathrm{g})\end{array}$ & $\begin{array}{l}\text { Bone ash }(g / 100 \\
\text { dry fat-free bone }\end{array}$ \\
\hline $\begin{array}{l}4 \\
4\end{array}$ & $\begin{array}{r}0 \\
10\end{array}$ & $\begin{array}{l}22 \\
22\end{array}$ & $\left.\begin{array}{r}8.5 \\
10.4\end{array}\right\} \pm 0.28$ & $\left.\begin{array}{l}36 \cdot 3 \\
46 \cdot 1\end{array}\right\} \pm 0 \cdot 40$ \\
\hline $\begin{array}{l}5 \\
5\end{array}$ & $\begin{array}{r}0 \\
10\end{array}$ & $\begin{array}{l}10 \\
10\end{array}$ & $\left.\begin{array}{r}8.6 \\
10.7\end{array}\right\} \pm 0.51$ & $\left.\begin{array}{l}34.2 \\
48.2\end{array}\right\} \pm 0.77$ \\
\hline $\begin{array}{l}7 \\
7\end{array}$ & $\begin{array}{r}0 \\
10\end{array}$ & $\begin{array}{l}\text { 10 } \\
\text { 10 }\end{array}$ & $\left.\begin{array}{l}6.6 \\
9.5\end{array}\right\} \pm 0.44$ & $\left.\begin{array}{l}31 \cdot 9 \\
49.4\end{array}\right\} \pm 0.73$ \\
\hline
\end{tabular}

\section{Histochemical changes}

The means of the histochemical scores and their standard errors are given in Table 2.

In the gut we examined the epithelium lining the mucosa and the mucosal glands. Colon mucosa showed no activity of the enzymes studied and ileum only pseudolipase. These two tissues were examined in the initial 4-week deprivation study only. In duodenum, lactate dehydrogenase was significantly $(P<0.05)$ higher in the deficient rat after 4 weeks' deprivation. There were no other differences. In the jejunum the phosphatases showed marked changes. After 4 and 7 weeks' deprivation, both alkaline $(P<0.05)$ and acid $(P<0.01)$ phosphatase levels were lowered in the deficient rat. The amount of glucose-6-phosphatase appeared to decrease 


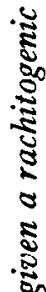

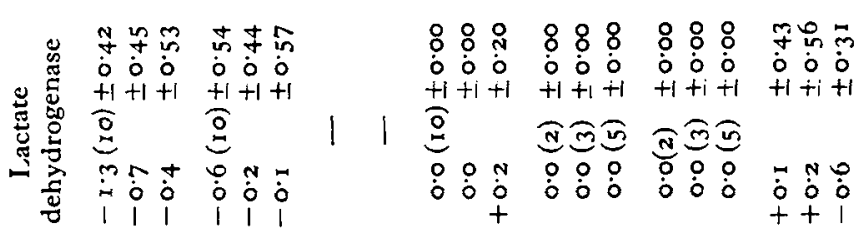

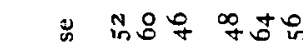

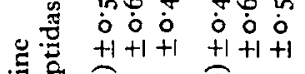

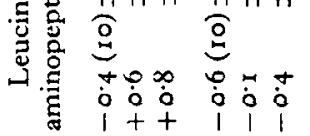

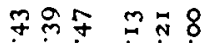

0 : 0 o $\dot{0} 0$

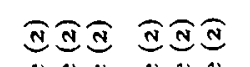

$+1+1+1+1+1+1$

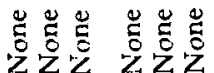

$\stackrel{0}{\circ}$

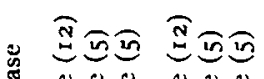

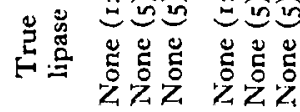

กูก

莡

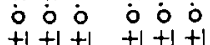

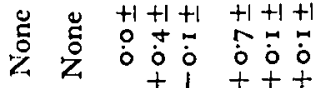

वंगे

$\dot{m}$

క్

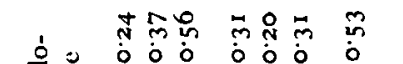

ํํㅇำ

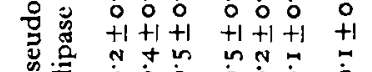

)

ڤn

0 o 0 o 0 o 0

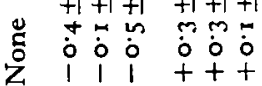

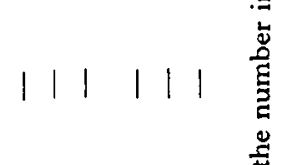

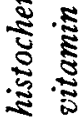

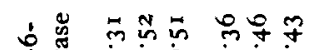

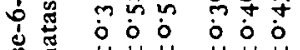

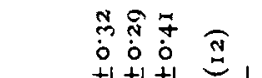

o $+1+1+1+1+1$

I

㕣范

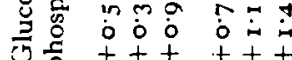

(2)

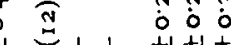

ปั

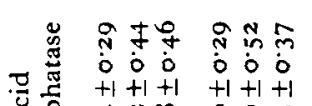

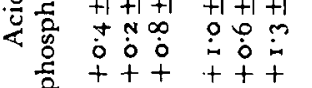

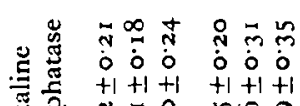

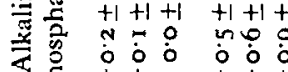

$\frac{\sqrt{2}}{2}$

远 1

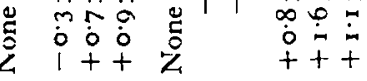

ह

옹

$\frac{1}{2 \pi}$

岇苛能

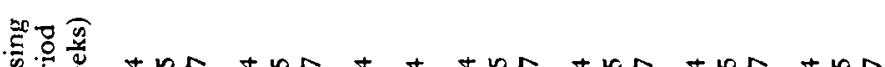

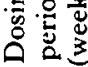

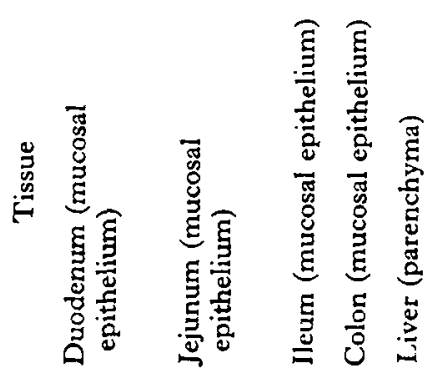

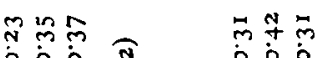

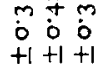

$+1+1+1=$

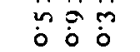

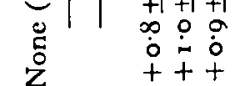

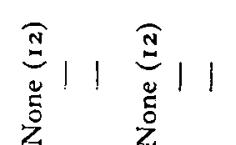

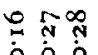

$\therefore \dot{0}$

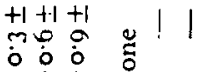

.

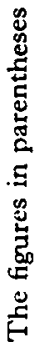

है

\&
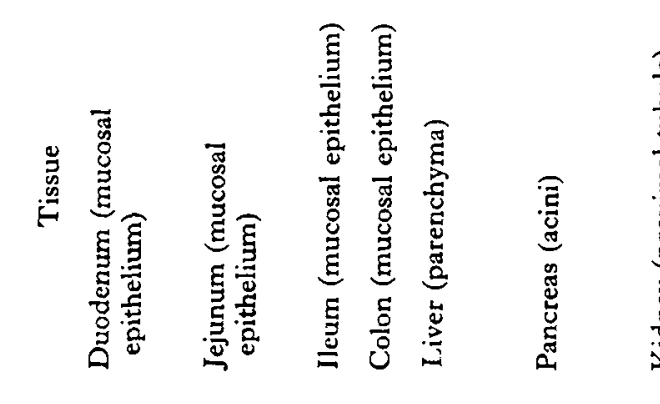

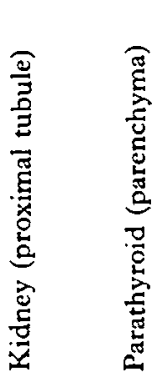


progressively as deprivation continued and this decrease became significant at $5(P<0.05)$ and $7(P<0.01)$ weeks.

In the pancreas only the acini were compared. True lipase decreased $(P<0.05)$ in the deprived rat after 4 weeks.

In the liver parenchyma, the content of acid phosphatase was raised in the deficient $(P<0.05)$ at 4 weeks but fell below the normal at 5 weeks $(P<0.05)$, and at 7 weeks the difference had disappeared. Glucose-6-phosphatase had decreased after 5 weeks deprivation $(P<0.05)$ and at 7 weeks was still almost significantly lower $(0.05<P$ $<0.1)$. The content of pseudolipase appeared to be higher in the deficient animals, but the difference only reached significance after 7 weeks $(P<0.05)$.

In the kidney cortex, with the incubation times used, phosphatases appeared only in the proximal tubules. The decrease in level of all phosphatases was marked, with the exception of that of alkaline phosphatase at 4 weeks, which failed to reach significance.

In the parathyroid, the content of leucine aminopeptidase rose in the deficient animal $(P<0.01)$ in all series.

\section{DISCUSSION}

The most striking histochemical change observed in these experiments was the rise in leucine aminopeptidase activity in the parathyroids of the deprived rats. Although it has been shown that the substrate is hydrolysed by peptidases other than leucine aminopeptidase (Sylvén \& Bois, 1962), it seems certain that the rise in enzyme activity can be equated with increased parathyroid activity. This was suggested by Pearse \& Tremblay (1958), who demonstrated a depression of leucine aminopeptidase activity in rat parathyroids after large doses of dihydrotachysterol, and a rise in leucine aminopeptidase activity after 3 weeks on a vitamin D-free, low-calcium, highphosphorus diet; comparison in both treatments was with rats of the same weight that had been maintained on a normal diet. In our experiments all the animals were on a high-calcium, low-phosphorus diet and therefore the rise in leucine aminopeptidase activity can only be attributed to the lack of vitamin $\mathrm{D}$, either acting directly on the parathyroid or indirectly through changes in the plasma calcium. This rise was restricted to the parathyroid; of the other tissues examined, none showed any change in leucine aminopeptidase activity. After 7 weeks' deprivation there was some indication that lactate dehydrogenase might have been increasing in the parathyroids of the deprived rats, but there were no changes earlier than this.

Of the two segments of gut examined, the jejunum appeared to be more sensitive to lack of vitamin $\mathrm{D}$ than the duodenum. This was expected since the jejunum is believed to be the main absorptive area and the site at which calcium and phosphate are transported against a concentration gradient (Harrison \& Harrison, 1960, 1961). The significance of the higher lactate dehydrogenase activity in the duodenum of the deprived rats at 4 weeks is at present difficult to explain. Since the difference between the pairs of animals appeared to diminish as the deficiency progressed, it may be of interest to examine duodenal dehydrogenase at earlier stages of deprivation.

The decline in jejunal phosphatase activity in the vitamin D-deficient rats was of a similar pattern to the decline in that of kidney phosphatases. Morton (1953) has 
shown that acid and alkaline phosphatases catalyse not only the hydrolysis of orthophosphomonoesters and phosphoamides but also the transfer of phosphate from these substrates to glucose, glucose-6-phosphate always being the product. It was suggested by Gutman \& Yu ( $\left.195^{\circ}\right)$ that alkaline phosphatase acts as a transferase in the calcification of cartilage. It is suggested that some transferase system incorporating all three phosphatases is involved in the transport of calcium and phosphate in both kidney and jejunum, particularly since phosphate esters are known to chelate calcium (Neuman \& Neuman, I958), and since Harrison \& Harrison (1961) have shown that there is a relationship between calcium and phosphate absorption in the isolated jejunum.

The pattern of enzyme changes in the liver alters with the duration of deprivation. It will be necessary to study changes earlier in deficiency before coming to any conclusion. The liver is known (Kodicek, 1956) to metabolize vitamin D, and the important role of the liver in digestion, absorption and metabolism makes it probable that it is affected by vitamin deficiency.

Pancreatic lipase, which showed a decrease after 4 weeks' deprivation but not after 5 and 7 weeks, also merits earlier examination.

In the discussion of our results we may have appeared to attribute the changes in the activity of enzymes directly to the lack of vitamin D. It is realized that they may equally be secondary to changes in parathyroid activity or to changes in plasma calcium or phosphate. A study of the earlier stages of deprivation may indicate which is the primary event.

\section{SUMMARY}

I. Eighty-four male black and white rats were given a rachitogenic diet with or without doses of vitamin D for 4,5 or 7 weeks. Histochemical study of certain tissues was used to trace enzyme changes associated with deficiency of vitamin D.

2. In the parathyroid gland leucine aminopeptidase activity was increased in all rats deficient in vitamin $D$.

3. In the kidney and the jejunum the activities of phosphatases decreased in rats deprived of vitamin $\mathrm{D}$.

4. Other changes were observed and are discussed.

\section{REFERENCES}

Bills, C. E., Honeywell, E. M., Wirick, A. M. \& Nussmeier, M. (1931). F. biol. Chem. $90,619$.

Blunt, A. D., Cheesman, E. M. \& Copping, A. M. (1957). Brit. F. Nutr. $11,62$.

Gutman, A. B. \& Yu, T. F. (1950). In Metabolic Interrelations. Transactions of the Second Conference, p. 167. New York: Josiah Macy Jr. Foundation.

Harrison, H. E. \& Harrison, H. C. (1960). Amer. Y. Physiol. 199, 265.

Harrison, H. E. \& Harrison, H. C. (1961). Amer. F. Physiol. 201, 1007.

Hume, E. M., Pickersgill, M. \& Gaffikin, M. M. (1932). Biochem. Ұ. 26, 488.

Kodicek, E. (1956). In Bone Structure and Metabolism. Ciba Foundation Symposium, p. I6r, Isondon: J. and A. Churchill.

Morton, R. K. (1953). Nature, Lond., 172, 65.

Neuman, W. F. \& Neuman, M. W. (1958). The Chemical Dynamics of Bone Mineral, p. I1. Chicago: The University of Chicago Press.

Pearse, A. G. E. (1960). Histochemistry. London: J. and A. Churchill.

Pearse, A. G. E. \& Tremblay, G. (1958). Nature, Lond., 181, 1532.

Steenbock, H. \& Black, A. (1925). F. biol. Chem. 64, 263.

Sylvén, B. \& Bois, I. (1962). Histochemie, 3, 65 . 